\title{
Malignant pleural mesothelioma
}

\author{
C. Boutin*+, M. Schlesser*, C. Frenay*, Ph. Astoul*+
}

\begin{abstract}
Malignant pleural mesothelioma. C. Boutin, M. Schlesser, C. Frenay, Ph. Astoul. @ERS Journals Ltd 1998.

ABSTRACT: The incidence of malignant pleural mesothelioma (MPM) has risen for some decades and is expected to peak between 2010 and 2020. Up to now, no single treatment has been proven to be effective and death usually occurs within about 1217 months after diagnosis. Perhaps because of this poor prognosis, early screening has incited little interest. However, certain forms may have a better prognosis when diagnosed early and treated by multimodal therapy or intrapleural immunotherapy. Diagnosis depends foremost on histological analysis of samples obtained by thoracoscopy. This procedure allows the best staging of the pleural cavity with an attempt to detect visceral pleural involvement, which is one of the most important prognostic factors. Although radiotherapy seems necessary and is efficient in preventing the malignant seeding after diagnostic procedures in patients, there has been no randomized phase III study showing the superiority of any treatment compared with another. However, for the early-stage disease (stage I) a logical therapeutic approach seems to be neoadjuvant intrapleural treatment using cytokines. For more advanced disease (stages II and III) resectability should be discussed with the thoracic surgeons and a multimodal treatment combining surgery, radiotherapy and chemotherapy should be proposed for a randomized controlled study. Palliative treatment is indicated for stage IV. In any case, each patient should be enrolled in a clinical trial. Eur Respir J 1998; 12: 972-981.
\end{abstract}

*Dept of Pulmonary Diseases, Hôpital de La Conception, Marseille, France. +UPRES 2050 (Environmental Pulmonary and Cutaneous Diseases), University of the Mediterranean, Marseille, France.

Correspondence: C. Boutin

Hôpital de la Conception

147 Bd Baille

13385 Marseille

Cedex 5

France

Fax: 33491383659

Keywords: Asbestos

cytokines

malignant mesothelioma

pleura

thoracoscopy

Received: April 171997

Accepted after revision July 281998
The term "mesothelioma" was first used in 1921 by EASTWOOD and MARTIN [1] to describe primary tumours of the pleura. At that time, the primary nature of these tumours was controversial without confirmation by autopsy. Today, the histological diagnosis of mesothelioma remains problematic and differential diagnosis against adenocarcinoma is difficult in $10-15 \%$ of cases despite the routine use of histochemistry.

The first evidence implicating asbestos in the pathogenesis of mesothelioma was presented in 1960 by WAGNER [2] in South African miners. The incidence of malignant pleural mesothelioma (MPM) has risen for some decades and is expected to peak sometime between 2010 and 2020 [3, 4]. This increase has been attributed to the widespread use of asbestos in the period from World War II until the end of the 1970s [5]. Pleural mesothelioma is more frequent than peritoneal mesothelioma, possibly because in-halation is the usual route of the pathogenic fibres.

No single treatment has been proven to be effective for malignant mesothelioma. Chemotherapy alone has no effect, radiation therapy simply provides palliation against pain, and surgery (even when performed at a relatively early stage) is controversial [6-10]. The value of the current staging system is questionable: after the first classification by BUTCHART et al. [8] the number of successive classifications provides evidence for the difficulty in distinguishing between the various stages of the disease [11-13].

Recent studies have reported good results using immunotherapy and surgery in patients graded as "early stage" according to a new system of classification $[14,15]$. The purpose of the present article is to describe the current knowledge on mesothelioma.

\section{Epidemiology}

In industrialized countries where asbestos was widely used from the end of World War II until the end of the 1970s, the incidence per year of mesothelioma is presently 2 per million in females and 10-30 per million in males [5]. Geographical variations in incidence are due to regional differences in industrial activity. Regions with

Previous articles in this series: No. 1: G. Miserocchi. Physiology and pathophysiology of pleural fluid turnover. Eur Respir J 1997; 10: 219-225. No. 2: R.W. Light. Diagnostic principles in pleural disease. Eur Respir J 1997; 10: 476-481. No. 3: G.T. Kinasewitz. Transudative effusions. Eur Respir J 1997; 10: 714-718. No. 4: J. Ferrer. Pleural tuberculosis. Eur Respir J 1997; 10: 942-947. No. 5: H. Hamm, R.W. Light. Parapneumonic effusion and empyema. Eur Respir J 1997; 10: 1150-1156. No. 6: G. Hillerdal. Chylothorax and pseudochylothorax. Eur Respir J 1997; 10: 1157-1162. No. 7: F.M.N.H. Schramel, P.E. Postmus, R.G.J.R.A. Vanderschueren. Current aspects of spontaneous pneumothorax. Eur Respir J 1997; 10: 1372-1379. No. 8: F. Rodriguez-Panadero, V.B. Antony. Pleurodesis: state of the art. Eur Respir J 1997; 10: 1648-1654. No. 9: S.A. Sahn. Pleural diseases related to metastatic malignancies. Eur Respir J 1997; 10: 1907-1913. No. 10: C. Kroegel, V.B. Antony. Immunology of pleural inflammation: potential implications for pathogenesis, diagnosis and therapy. Eur Respir J 1997; 10: 2411-2418. No. 11: R.W. Light, H. Hamm. Pleural disease and acquired immune deficiency syndrome. Eur Respir J 1997; 10: 2638-2643. No. 12: R. Loddenkemper. Thoracoscopy - state of the art. Eur Respir J 1998; 11 : $213-221$. 
shipyards are at particularly high risk [16]. Another factor influencing incidence is the type of fibre used, the incidence being higher with crocidolite and amosite than with chrysotile [17-19]. Details on occupational risks have been reviewed recently [20].

In France, the exact incidence of mesothelioma is not known since there is no national register for the disease. According to a recent review by the National French Institute for Medical Research (INSERM) [19] 950 new cases per year are probably observed. In the authors region (south-east France, which has a large number of shipyards) a study performed between 1989 and 1993 indicated an annual incidence of 14.2 per million in males and 1 per million in females in the Provence region and 1 per million in females and 16.2 per million in males in Corsica [21]. In Paris and suburbs [22] the incidence rate is 7.5 per million for males and 1.5 per million for females. In the USA the highest published annual rate per million is 13.3 $[23,24]$ for males and 2.5 for females and in Australia the rates are 66 per million for males and 7 per million for females [25].

In most other industrialized countries (e.g. Sweden, Canada, Australia, the Netherlands) the annual incidence increased 3.5-fold for males and 1.4-fold for females from the end of the 1960s to the beginning of the 1980s [2628]. In the UK the epidemic will peak at about 2,700 deaths per year and will disappear rapidly after 2020 [4]. The USA epidemic has already reached its peak [29]: since 1980 USA rates have declined in both sexes.

Despite their unreliability these data seem to indicate a major increase in the annual incidence of mesothelioma in males and a smaller increase in females. This trend will probably continue in many countries until the second decade of the 21 st century. The long latency period for the development of mesothelioma accounts for the rising incidence of mesothelioma for up to 30-40 yrs after application of strict laws on the use of asbestos.

The high sex prevalence for males in most countries is strong evidence for occupational exposure to asbestos, since females are less likely to have worked in contaminated areas. Mesothelioma due to nonoccupational environmental exposure has been reported in various places including Corsica [21], New Caledonia [30], Cyprus [31], Greece [32] and Turkey [33]. Cases due to exposure in buildings with asbestos insulation seem to be extremely rare $[34,35]$.

\section{Pathogenicity of asbestos fibres}

Asbestos fibres that reach the respiratory bronchioles and alveoli are subject to different fates. Chrysotile fibres can undergo fragmentation by organic acids, and progressive clearance, whereas amphibole fibres may remain unchanged for decades [36]. High concentrations of asbestos fibres in the lung are associated with asbestosis and bronchial carcinoma [37]. In patients with these conditions, asbestos bodies, mostly formed on amphibole fibres, are usually found in lung sections and bronchoalveolar lavage fluid [38]. Fibres may also migrate towards the periphery of the lung, especially the lower lobes [39], into mediastinal lymph nodes [40] and the pleura.

Benign pleural plaques are the most common manifestation of asbestos exposure [26]. They usually develop on the parietal or diaphragmatic pleura. Malignant pleural mesothelioma probably also originates from the parietal pleura. Up to now, however, very few studies have detected significant amounts of asbestos fibres in the parietal pleura [18]. Experiments by STANTON et al. [41] demonstrated that the risk for mesothelioma is related to the concentration of long $(>8 \mu \mathrm{m})$ amphibole fibres. Other animal experiments using intracavitary injections of asbestos confirmed that the most carcinogenic fibres were those measuring $>5 \mathrm{~mm}$ in length and $<0.25 \mathrm{~mm}$ in diameter [42, 43]. In sharp contrast to these data, all previous mineralogical studies have shown that short chrysotile fibres are the most common type of asbestos present in the parietal pleura [44], where amphibole fibres meeting the criteria of Stanton for carcinogenicity are uncommon or absent [45].

A possible explanation for this paradox could be that fibres are heterogeneously distributed in the parietal pleura. This would explain why random sampling in unselected areas yields poor concentrations. Indeed, when samples were taken from pathological zones such as pleural plaques or tumours [46], more fibres were found.

Several findings led to the speculation that these asbestos fibres could accumulate in certain areas of the parietal pleura. In mice, subcutaneously injected fibres are known to concentrate in the milky spots of the parietal pleura [47]. In humans, milky spots are almost invisible in the healthy pleura. However, thoracoscopy sometimes visualizes foci of parietal anthracosis near lymphatic vessels of parietal pleura [48], which have been called "black spots". Indeed, these black spots could correspond to the milky spots described by KANAZAWA et al. [47] in mice and be rendered visible by trapped coal dust.

Thoracoscopic biopsy samples were collected from these black spots [18] and from normal areas of the parietal pleura and lung from 14 subjects (eight with and six without asbestos exposure). Asbestos content was determined by transmission electron microscopy. In exposed subjects mean fibre concentrations were $12.4 \pm 9.8 \times 10^{6}$ fibres.g of dry tissue $\mathrm{e}^{-1}$ in lung, $4.1 \pm 1.9$ in black spots and $0.5 \pm 0.2$ in normal pleura. In unexposed patients, these concentrations were $0,0.3 \pm 0.1$ and 0 , respectively. Amphiboles outnumbered chrysotile in all samples. A total of $22.5 \%$ of the fibres were $>5 \mathrm{~mm}$ in length in black spots. These findings could explain why the parietal pleura is the target organ for mesothelioma and plaques.

\section{Clinical manifestations}

The mean age of patients is approximately $60 \mathrm{yrs}$. A few cases have been described before the fourth decade of life in patients exposed to asbestos during childhood. The tumour can occur rarely in children [49] and a number of these cases probably has no relation to asbestos. The previously mentioned strong male predominance is due to the fact that exposure to asbestos is less common in females.

Clinical manifestations depend on the stage of the disease. Recently, an international staging system was proposed by the International Mesothelioma Interest Group (IMIG) on a new tumour, node, metastasis (TNM) basis [12] (table 1). In early-stage disease general symptoms such as fatigue, weakness and weight loss are rare (15\%) [50]. The pain which is extremely frequent in advanced 
Table 1. - New international staging system for diffuse malignant pleural mesothelioma

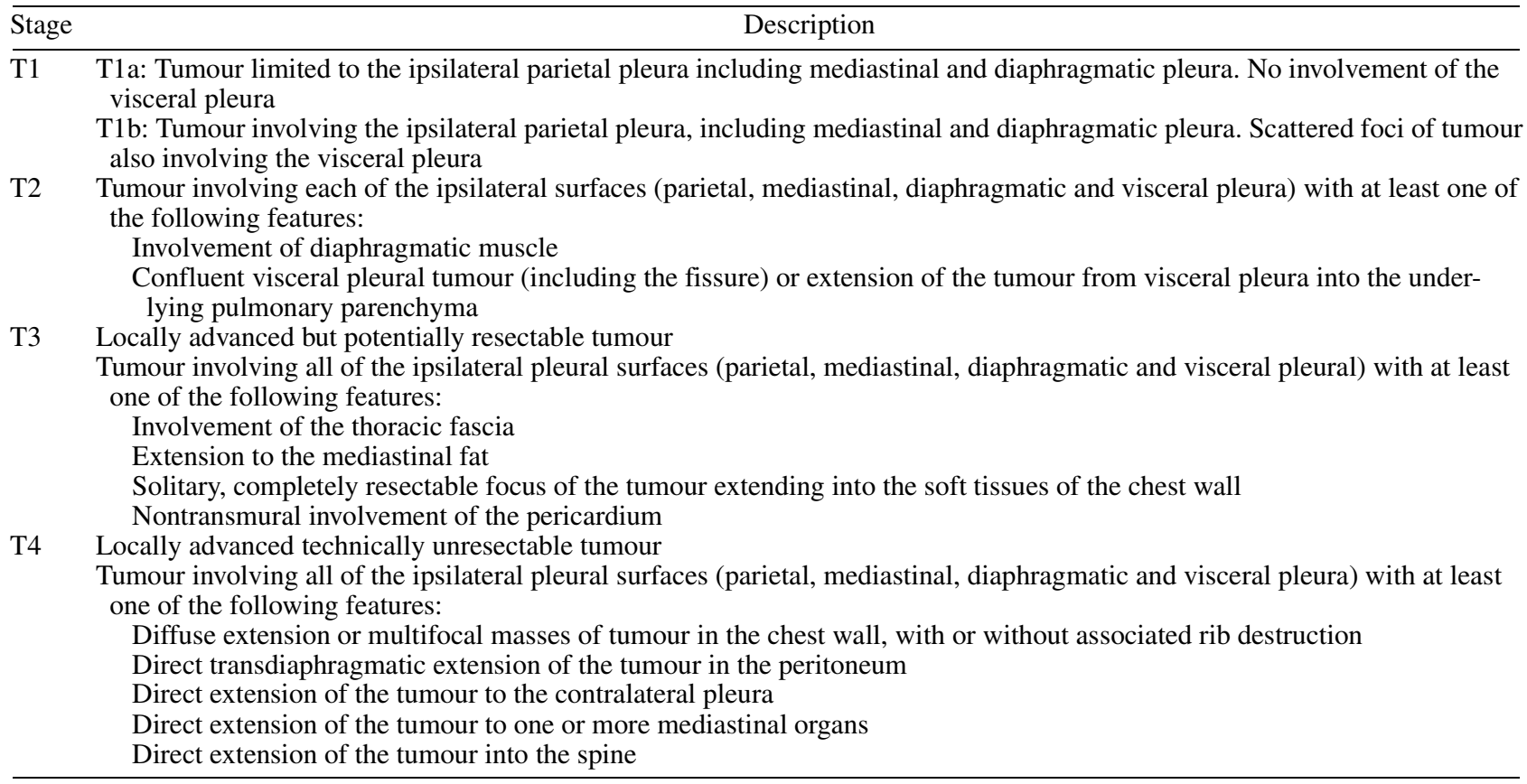

(From International Mesothelioma Interest Group [12].)

stages is less common in stage Ia. In contradiction to descriptions given in manuals pleurisy may be unremarkable and often occurs without radiologically detectable tumour. Massive effusion at the time of presentation is possible, but moderate effusion is more likely. The fact that pleurisy may not recur for weeks or months after initial drainage can lead to a delay in diagnosis. Moderate tightness followed by progressive pain, cough and shortness of breath are the most common presenting signs. Since the symptoms are nonspecific, practitioners in regions exposed to industrial or environmental asbestos fibres should keep mesothelioma in mind and not rule out the possibility even if the initial cytological or histological findings are negative.

In our series the initial thoracic radiograph leading to a diagnosis of mesothelioma showed a pleural effusion in $92 \%$ of cases, where the thoracentesis showed a clear or haemorrhagic fluid [50]. In $0.5 \%$ thoracentesis revealed an empyema. Radiography showed in $0.5 \%$ a spontaneous pneumothorax and in $7 \%$ multinodular pleural tumour without fluid. Three patients had a history of radiation therapy for lymphoma. An association between irradiation of the thorax and mesothelioma has been reported previously [51]. In another series [27] only $1 \%$ of diagnoses were made coincidentally on routine radiographic images with no thoracic symptoms.

The pleural fluid is an exudate with little evidence of inflammation: cell counts reveal a high number of mesothelial cells [52] without a significant increase in neutrophils or lymphocytes. Cytological examination of pleural effusions, which is one of the first diagnostic techniques attempted in patients with MPM, is usually positive in only $30 \%$ of the cases [53].

At stage I, pleural effusion is the prominent feature seen on radiography and computed tomographic (CT) scan. This is not specific. Removal of fluid improves the recognition of more specific signs: irregular or nodular pleural thickening is the more frequent feature seen on the CT scan [54] (fig. 1). Spread of the tumour is difficult to assess for staging or evaluation of treatment response in the following sites: diaphragmatic pleura, chest wall, pericardium, mediastinum and lymph nodes [55-57].

Thoracoscopy allows assessment of the parietal and visceral pleura and is the most reliable method by which to achieve early diagnosis. CT scan and thoracoscopy are complementary for establishing classification and prognosis [56]. Magnetic resonance imaging (MRI) seems to be promising $[57,58]$.

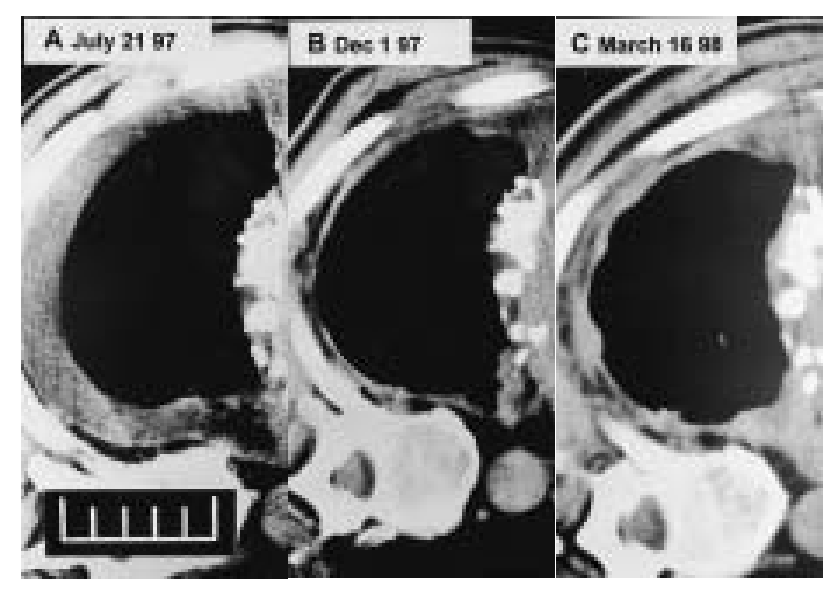

Fig. 1. - Successive computed tomographic scans in a mesothelioma patient at stage I. A) Pleural effusion without any specific aspect. The patient received steroids for 2 months; B) resolution of the effusion. Small nodules are seen in the costovertebral gutter; C) evolution after 3 months, showing several nodules on the parietal pleura. (Internal scale bar $=50 \mathrm{~mm}$.) 


\section{Diagnosis}

In our series [50, 59] diagnosis was achieved by cytology alone in $26 \%$ of cases, by closed pleural biopsy in $20.7 \%$ and by a combination of the two methods in $38.7 \%$. These poor results are comparable to those obtained in previous studies with the Cope needle [60]. A recent trial in which immunohistochemical markers were used in an effort to improve the results of blind biopsy was disappointing [52].

Medical diagnostic thoracoscopy is indicated in any patient without precise histopathological diagnosis in whom clinical and laboratory findings raise the suspicion of mesothelioma: cardinal characteristics are age between 55 and $60 \mathrm{yrs}$, previous exposure to asbestos, pleural effusion or radiological images showing irregular and nodular lesions of the parietal pleura, especially in the posterior and inferior part of the costovertebral gutter.

Macroscopically, the lesions range from 1-3 $\mathrm{mm}$ to 1 $\mathrm{cm}$, in diameter or even larger, depending on the stage. In most patients nodules and masses are associated with parietal pleural thickening up to several millimetres. In $20 \%$ of cases nodules are small (1-5 mm in diameters). A typical aspect of mesothelioma is the grape-like aspect, which consists of a patch of closely spaced, smooth, translucid, poorly vascularized nodules $5-10 \mathrm{~mm}$ in diameter with a clear or yellowish appearance. Upon biopsy these lesions may either be friable and filled with sticky fluid or hard and difficult to remove. The grape-like aspect is typical of mesothelioma, generally at the advanced stage, but it is not specific since it is also encountered in patients with metastatic cancer of the pleura. Unlike benign inflammation, malignant thickening of the pleura associated with mesothelioma is hard and unelastic. When biopsy samples are taken, the cut edge is clear and there is little or no bleeding.

In $10-15 \%$ of all cases and in $50 \%$ of stage Ia cases [50], the lesions observed during thoracoscopy are macroscopically nonspecific: benign inflammation of the parietal or diaphragmatic pleura with lymphangitis in some cases. In these cases a more discrete sign is irregular thickening located mainly in the posterior and inferior region of the parietal pleura, where lymphatic vessels are most numerous. The more nonspecific the lesions, the more biopsies should be taken (up to 15 or 20).

An important diagnostic finding is the involvement of the visceral pleura and lung [59]. These structures can be easily visualized during thoracoscopy. The visceral pleura is always less involved than the parietal pleura, with nod- ules being not only less numerous but also smaller. In many cases the visceral pleura appears macroscopically normal but routine biopsy should be performed to confirm or exclude the diagnosis.

Histological diagnosis is problematic because of structural variability between different tumours and even within the same tumour. Furthermore, differential diagnosis with adenocarcinoma is often difficult. Mesothelioma is classified into various major histological types, i.e. epithelial, sarcomatous, mixed and desmoplastic. The cell pattern of epithelial tumours can be tubular, papillary or more complex and differential diagnosis with reactive mesothelial cells can require histochemical or immunohistochemical techniques and even electron microscopy [61-64]. Diagnosis is further complicated by the fact that involvement of the pleura is patchy and histological findings can vary from one place to another. In this regard sampling must be extensive, focusing on the most suspicious areas, especially for the desmoplastic type.

In our series medical thoracoscopy allowed diagnosis in 185 of 188 cases $(98.4 \%)$ [50]. The three failures occurred when artificial pneumothorax was impossible to realize, precluding the access to the pleural cavity. Thoracoscopy is currently the technique of choice for the diagnosis of mesothelioma and thoracotomy should be resorted to only when medical thoracoscopy is unfeasible or inadequate. Thoracoscopy is a safe technique [65]. Mortality is 1: 8,000 and complications are uncommon and usually minor (subcutaneous emphysema, localized pleural infection and minor bleeding, $<100 \mathrm{~mL}$ ). The only major problem associated with medical thoracoscopy in patients with mesothelioma is seeding of the chest wall along the path of insertion of the trocar. Seeding, which has also been observed after thoracenteses or blind pleural biopsies, can be prevented by performing prophylactic radiotherapy after healing of the point of entry [66].

\section{Prognosis and classification}

Median survival ranges from 12 to 17 months depending on the series $[67,68]$, while 5-yr survival is less than $5 \%$. Several large studies involving multivariate analysis have identified several factors for a more favourable prognosis (table 2). More recently, an absence of weight loss at the time of diagnosis, absence of involvement of the visceral pleura, stage I and epithelial histopathological type were found to be the most favourable factors in an analysis according to a Cox model [59]. The absence of symptoms in general and pain in particular depends on the stage.

Table 2. - Multifactorial analysis of prognostic factors for malignant pleural mesothelioma: data from the literature

\begin{tabular}{|c|c|c|c|c|c|c|}
\hline & \multicolumn{6}{|c|}{ First author [ref.] } \\
\hline & $\begin{array}{c}\text { CHAHINIAN } \\
{[68]}\end{array}$ & $\begin{array}{c}\text { ALBERTS } \\
{[10]}\end{array}$ & $\begin{array}{c}\text { ANTMAN } \\
{[67]}\end{array}$ & $\begin{array}{l}\text { RuFHIÉ } \\
{[27]}\end{array}$ & $\begin{array}{c}\text { RusCH } \\
{[6]}\end{array}$ & $\begin{array}{c}\text { Boutin } \\
\text { [59] }\end{array}$ \\
\hline Year & 1982 & 1988 & 1988 & 1989 & 1991 & 1993 \\
\hline Patients $\mathrm{n}$ & 57 & 262 & 136 & 170 & 83 & 188 \\
\hline Median survival months & 13 & 9.6 & 15 & 9 & 10 & 16 \\
\hline \multirow{5}{*}{ Favourable factors } & Epithelial & PS & PS & Stage I & None & Epithelial \\
\hline & Age $<65$ yrs & Treatment & Epithelial & Platelets & & Stage Ia \\
\hline & PS & White race & No chest pain & No weight loss & & PS \\
\hline & Surgery & Sdg $>6$ months & Sdg $>6$ months & & & Lesions $<5 \mathrm{~mm}$ \\
\hline & Response CT & Stage I & Surgery & & & \\
\hline
\end{tabular}

PS: Performance status; Sdg: interval between first symptom and diagnosis; CT: computed tomography. 
The first published classification by BuTCHART et al. [8] is frequently used owing to its simplicity. However the early stage of malignant pleural mesothelioma is not part of this classification. Thus, different types of stage I are mixed in that classification. Spontaneous survival is long-er if the visceral pleura and the lung are not invaded (stage Ia) and careful examination of visceral pleura must be conducted during thoracoscopy [12]. Several classification systems have been proposed for mesothelioma [11].

The most recent system is the TNM classification of the IMIG [12]. This TNM classification is close to the one proposed by CHAHINIAN [69] and includes a full range of stages from an isolated lesion of the parietal pleura or diaphragm (stage Ia, as previously mentioned) to advanced-stage mesothelioma. The main advantage of this classification is to provide clinicians with a standard allowing comparison of study data and results. Although this TNM system still requires further refinement, it constitutes a solid foundation. However, several remarks may be made concerning this system. One point of discussion is the importance of node status. In the series of SUGARBaKer et al. [70] the long survival of patients without node involvement (N0) could have been due to the fact that these patients had earlier stage disease. Since metastasis is an uncommon late occurrence, it is not an important criterion in the classification. It must also be determined whether the TNM classification should be clinical, made on the basis of endoscopic and radiological findings, or postoperative, made on the basis of surgical findings. It should also be said that the distinction between T2 and T3 is of little practical value since the difference in survival is minimal, as shown in a recent series [13].

\section{Evolution}

As previously mentioned, the possible disappearance of the initial effusion after drainage is a special feature of early mesothelioma. Owing to this misleading development the disease may be wrongly diagnosed as benign pleurisy and allowed to progress untreated for up to $1 \mathrm{yr}$ or more. Thus, caution is always necessary with regard to the diagnosis of benign pleurisy in subjects between the ages of 50 and 60 yrs with a history of exposure to asbestos and for these patients early thoracoscopy is required.

Mesothelioma develops locally, sometimes for a long time, before invading surrounding organs. Diaphragm and lung involvement usually occur first, with progressive retraction of the hemithorax and development of trapped lung. Involvement of the liver occurs later. The peritoneum is infiltrated either through the diaphragm or through its posterior openings with secondary ascites. Paraneoplastic syndrome is uncommon; this involves migrating phlebitis, thrombocytosis, haemolytic anaemia, hypoglycaemia, hypercalcaemia and pulmonary hypertrophic osteoarthropathy.

Spreading to the endothoracic fascia (T2) and intercostal spaces (T3) is frequent and has been noted in 30-50\% of patients who have undergone invasive surgical or diagnostic procedures (e.g. thoracentesis and biopsy). Parietal involvement can be massive and painful and parietal pain is extremely frequent.

Clinically detectable secondary lesions in bone, subcutaneous and brain sites are uncommon, as is involvement of the contralateral pleura or lung. However, it should be noted that metastasis is more frequent after surgery, more often after pleuropneumonectomy than after pleurectomy $[71,72]$. According to the authors this could reflect the disease stage and prevalence of nodal stages. However, it can also be hypothesized that during thoracotomy handling of tumour tissue releases isolated cells into blood and perhaps lymphatic circulation. Our pathologists found a large number of isolated cells in the washing of the pleural cavity after pleurectomy or pleuropneumonectomy. To reduce the risk of metastasis the surgeon must carefully wash the operative cavity after resection. At autopsy metastatic spread has been observed in 50\% of patients [73] Death is usually due to progressive dyspnoea and respiratory insufficiency with extensive weight loss and muscle wasting.

\section{Treatment}

\section{Surgery}

To ensure that surgery will be as curative as possible, it should be emphasized that resection must include the pleura (in stage Ia) and lung (in stages Ib, II and III) and in many cases the diaphragm, pericardium and portion of chest wall. Under these conditions it may be rightfully asked whether surgery actually improves the survival of patients. WörN [74] reported a series of 248 surgical cases in which survival was the same after palliative and curative surgery. PROBST et al. [75] described a series of 111 patients in which median survival was longer after extended pneumonectomy than other methods, but the difference was only 1.4 months. Since operative mortality is high, pat-ients must be selected carefully (age $<60$ yrs, early-stage disease, epithelial histology). However, even after careful selection the 5-yr survival is only $11 \%$. The main reason for these disappointing results is that complete resection is possible only in patients with early-stage disease with no mediastinal lymph node involvement. However, such cas-es are uncommon and surgeons are rarely satisfied because most resections remain incomplete. Rusch and coworkers [13, 71] reported better results after pleurectomy (18.3 month survival) than after extrapleural pneumonectomy (9.9 month survival), but this procedure often leaves residual malignant tumour in the lung or visceral pleura.

A review of surgical series suggests that treatment protocols including surgery extend survival. The median $2-\mathrm{yr}$ survival rate is $11-35 \%$ after pleurectomy and $10-37 \%$ after extrapleural pneumonectomy. These findings have been confirmed by the only prospective study involving pneumonectomy without postoperative treatment, in which 2 yr survival was $33 \%$ and median survival was 10 months [76]. Is surgery really useful for the patients? Can it be curative and able to prolong survival? It is impossible at the present time to ascertain whether survival is improved after radical surgery. A prospective randomized, phase III study is needed to answer this question.

\section{Radiation therapy}

Although radiation therapy has shown efficacy on mesothelioma cell lines [77], it has proven disappointing in 
mesothelioma patients and poor results have been described in several series $[78,79]$. One of the major problems in performing radiation therapy is determining the volume of the target area, which includes the diaphragm, mediastinum, and chest wall and excludes the lung.

Radiation therapy is also performed palliatively [80] to control pain. Irradiation is effective when pain is due to a direct extension of the tumour into the chest wall and ribs. Conversely, it is not effective and may even be harmful if pain originates from compression of the intercostal nerve as a result of retraction of the chest wall. Postradiation fibrosis can aggravate pain in these cases.

Prophylactic local radiation therapy to prevent parietal seeding after diagnostic examinations has been shown to be effective $[66,81]$. After thoracoscopy we wait for 1012 days to allow the point of entry to heal and then apply $21 \mathrm{~Gy}$ in three sessions of $7 \mathrm{~Gy}$ each over $48 \mathrm{~h}$. Target fields of $4-12 \mathrm{~cm}$ on each side are selected around the incision, drainage and previous puncture scars. A randomized trial of this technique was carried out in 40 patients with mesothelioma [66]. Seeding was not observed in any of the 20 patients who underwent prophylactic radiation therapy, whereas seeding was observed in eight of the 20 patients who did not undergo prophylactic radiation therapy. Based on these findings we now perform prophylactic radiation therapy routinely after thoracoscopy and have not observed any seeding at entry or drainage sites.

\section{Chemotherapy}

Chemotherapy has also been disappointing in patients with mesothelioma. In the best series, objective responses after single-agent treatment were achieved in 20-30\% of cases, but there was no significant impact on overall survival.

Despite their good reputation, doxorubicin and other anthracyclines achieve responses in no more than $15 \%$ of cases [82]. Similarly, cisplatin alone achieves a response rate of only $14 \%$ of cases at standard dosage and up to $33 \%$ at high dosage [83-87]. High doses of methotrexate alone obtain responses in $37 \%$ of cases [88].

Several groups began using cisplatin-mitomycin after a randomized study showing that it was more effective than doxorubicin-cisplatin [89]. A response rate of $44 \%$ was reported with mitomycin-bleomycin-cysplatin-doxorubicin combined with systemic and intrapleural hyaluronidase [90]. A response rate of $66 \%$ was obtained using high-dose methotrexate and folinic acid with vincristine or cisplatin [91]. A combined protocol involving platinum-mitomycin5-fluorouracil and etoposide (PMFE) was tested and responses were obtained in $33 \%$ of cases [92].

Table 3 summarizes the complete and partial response rates obtained using single-agent chemotherapy protocols and table 4 summarizes studies in which response rates of $25 \%$ or more were achieved using combined-agent protocols. The overall results of chemotherapy alone have been disappointing since it has had no clear-cut effect on survival.

\section{Intrapleural treatment (immunotherapy)}

Intrapleural immunotherapy is a new weapon in the arsenal against mesothelioma [93]. The antitumoural action
Table 3. - Response rates (complete or partial) after single-agent chemotherapy

\begin{tabular}{llr}
\hline Class & Agent & $\begin{array}{r}\text { Response rate } \\
\%\end{array}$ \\
\hline Anthracyclines & Doxorubicin & $0-40$ \\
& Pirarubicin & 22 \\
& Detorubicin & 26 \\
& Epirubicin & $5-15$ \\
Antimetabolites & Mitoxantrone & 3 \\
& Methotrexate hd & 37 \\
& 5-Fluorouracil & 5 \\
Alkylants & Edatrexate & 25 \\
& Trimetrexate & 12 \\
& Cisplatin & 14 \\
& Cisplatin hd & $13-33$ \\
& Carboplatin & $7-16$ \\
& Cyclophosphamide & 0 \\
Alkaloids & Ifosphamide & $3-24$ \\
& Mitomycin & 21 \\
& Vincristine & 0 \\
& Vindesine & $0-65$ \\
& Etoposide & $0-41$ \\
\hline
\end{tabular}

hd: high dose.

of immunotherapy is complex and remains poorly understood. Two cytokines, interferon-gamma (IFN- $\gamma$ ) and interleukin-2 (IL-2), have been tested in patients with malignant mesothelioma and have shown several objective antitumoural responses [15, 94].

One property of interferon is its ability to facilitate cell differentiation [95]. This mechanism could explain the efficacy of interferon on pleural mesothelial cell cultures [96]. Moreover, several studies have shown a possible direct cytotoxic effect on mesothelial cells [97-99] and stimulation of the activity of natural killer lymphocytes and macrophages [100-102].

The rationale for using IL-2 is based on the fact that it activates lymphokine-activated killer (LAK) cells and induces a cytolytic response [103]. In vitro studies have shown that human natural killer (NK) cell activity is suppressed by asbestos fibres, but restored by IL-2 [104], and human malignant mesothelioma cells lines were reported to be lysed by NK and LAK cells [105].

The intrapleural route of administration has several advantages. The pleural cavity acts as a reservoir where the injected drugs remain concentrated for several days or

Table 4. - Response rates Š25\% after combined chemotherapy

\section{Combined-agent protocol}

Doxorubicin-dacarbazine

Doxorubicin-cisplatin

Doxorubicin-cyclophosphamide-cisplatin

Doxorubicin-cyclophosphamide-vincristine

Doxorubicin-cyclophosphamide-vincristine-dacarbazine

Doxorubicin-ifosphamide

Doxorubicin-vincristine-methotrexate

Mitomycin-cisplatin

Cyclophosphamide-vincristine-5-fluorouracil-methotrexate

Cisplatin-R-fluorouracil-mitomycin-etoposide

Mitomycin-bleomycin-cisplatin-doxorubicin+hyaluronidase

Methotrexate hd-vincristine

Methotrexate hd-cisplatin

Doxorubicin-vincristine-methotrexate 
weeks [106]. This limits side-effects and ensures that the drug is applied to the tumour site.

Since 1987, more than 150 patients have been treated via the intrapleural route with either IL-2 [107] or IFN- $\gamma$ [15]. No data are available showing that one of these drugs is superior to the other and that the combination allows an increasing number of objective responses. INF- $\gamma$ was infused at a dose of $40 \times 10^{6}$ IU for $6 \mathrm{~h}$ twice a week for 8 weeks [15]. IL-2 was infused continuously for 5 days at a mean dose of $21 \times 10^{6} \mathrm{IU} \cdot$ day $^{-1}$ for 5 days [107]. Infusion was performed through an implantable port to avoid multiple punctures and infection [108].

The predictive factors for a good outcome of intrapleural immunotherapy appear to be as follows. 1) Stage: the overall percentage of complete or partial responses for the patients treated with IFN- $\gamma$ was $19.1 \%$, but the response rate varied greatly depending on disease stage; $44.8 \%$ of patients with stage I disease and $6 \%$ of patients with stage II disease achieved responses. The mean duration of partial responses was 19 months. For 22 patients treated with IL-2, one complete response and 11 partial responses (two with stage I and nine with stage II) were seen. The median \pm SE survival time of responders differed significantly from that of nonresponders: $28 \pm 12.12$ and $8 \pm 5.07$ months, respectively $(\mathrm{p}<0.01)$. The 24 - and 36 -month survival rates of responders were $58 \%$ and $41 \%$, respectively [109]. 2) Tumour size: the best results have been achieved in patients with nodules $<5 \mathrm{~mm}$ in diameter. 3) Epithelial histological type: immunotherapy failed quickly in two patients with fibrosarcomatous mesothelioma. 4) Absence of weight loss at the time of diagnosis.

\section{Gene therapy}

Recently, trials have been carried out in mesothelioma patients to evaluate gene therapy consisting of transfer of the thymidine kinase gene from herpes virus using adenovirus $[110,111]$. It is too early to judge the outcome of these trials.

\section{Multimodal treatment}

In view of the poor results obtained with the different treatments used individually, ANTMAN et al. [112] prop-osed a multimodal approach at the beginning of the 1980s. In their series of 180 patients the best results were ob-tained by combining extrapleural pneumonectomy with chemotherapy and radiation therapy. Survival was longer in patients with early-stage epithelial tumours. The best results reported so far were by SUGARBAKER et al. [14, 72], who obtained a 5-yr survival rate of $45 \%$ in a group of patients with epithelial mesothelioma without mediastinal lymph node involvement. Rusch and VenKatraman [13] also reported excellent local control in six of 13 patients treated by pleuropneumonectomy followed by radiation therapy. However, it should be noted that in The series of Rusch and VenKatraman [13] distant recurrences were observed in 11 patients, indicating that after surgery mesothelioma may become a generalized disease that requires systemic treatment.

\section{Conclusions}

Early-stage disease appears to be the most important factor for the success of treatment. The only way to ach- ieve early diagnosis in industrialized countries and geographically exposed areas is to bear in mind the possibility of mesothelioma in any patient with pleural fluid who was exposed to asbestos 30 yrs earlier. This possibility should not be ruled out even if the patient does not present with fibrohyalin or calcified pleural plaques.

After diagnostic procedures, prophylactic local radiation therapy is always recommended to prevent spreading to the wall or secondary sites.

In stage I and especially stage Ia, the disease is still intrapleural and thus can be treated by neoadjuvant intrapleural treatment. Pilot studies are still under way but pharmacological assays have consistently shown that intrapleural concentrations are up to 1,000 times higher than serum concentrations. This enhancement of drug concentration greatly increases the chance of obtaining a response. Both IFN- $\gamma$ and IL-2 have shown promising results in prospective phase I-II trials. The best response is seen in epithelial type mesothelioma with nodules or thickening not $>5 \mathrm{~mm}$, in patients whose general status is still good. However, such results must be confirmed in comparative studies with surgery.

The role of adjuvant surgery performed after intrapleural treatment to improve local control (pleurectomy or extended pleuropneumonectomy) or adjuvant chemotherapy to prevent distant metastasis is still unknown and further studies are needed.

In patients with stage II and III mesothelioma no randomized study has shown the superiority of any treatment over another; thus, the clinician has the choice between: a multimodal approach including radical surgery, radiation therapy, and chemotherapy. The result depends on the expertise of the surgeons to maintain low perioperative mortality (range 4-8\%); and a medical treatment including talc pleurodesis if necessary [113], palliative radiation therapy and combined chemotherapy, taking into account that no regimen has shown a superiority.

In patients with stage IV disease only conservative, palliative treatment to control pain is indicated.

Mesothelioma is difficult to detect at an early stage. Nevertheless, early detection is the key to prolonged survival. All possible diagnostic modalities must be applied to achieve this end. Thoracoscopy appears to be one of the most effective diagnostic techniques.

\section{References}

1. Eastwood EH, Martin JP. A case of primary tumour of the pleura. Lancet 1921; i: 172.

2. Wagner JC. Diffuse pleural mesothelioma and asbestos exposure in the North-West Cape Province. Br J Ind Med 1960; 17: 260-271.

3. Walker AM, Loughlin JE, Friedlander ER, Rothman KJ, Dreyer NA. Projections of asbestos-related disease 19802009. J Occup Med 1983; 25: 409-425.

4. Peto J, Hodgson JT, Matthews FE, Jones JR. Continuing increase in mesothelioma mortality in Britain. Lancet 1995; 345: 535-539.

5. McDonald AD, McDonald JC. Epidemiology of malignant mesothelioma. In: Antman K, Aisner J, eds. Asbestos-related Malignancy. Orlando, Grune and Stratton, 1987; pp. 31-55.

6. Rucsh VW, Piantadosi S, Holmes EC. The role of extrapleural pneumonectomy in malignant pleural mesothel- 
ioma. A lung cancer study group trial. $J$ Thorac Cardiovasc Surg 1991; 102: 1-9.

7. Brenner J, Sordillo PP, Magill GB, Golbey RB. Malignant mesothelioma of the pleura. Review of 123 patients. Cancer 1982; 49: 2431-2435.

8. Butchart EG, Ashcroft T, Barnsley WC, Holden MP. Pleuropneumonectomy in the management of diffuse malignant mesothelioma of the pleura: experience with 29 patients. Thorax 1976; 31: 15-24.

9. Law MR, Gregor A, Hodson ME, Bloom HJG, TurnerWarwick M. Malignant mesothelioma of the pleura: a study of 52 treated and 64 untreated patients. Thorax 1984; 39: 255-259.

10. Alberts AS, Falkson G, Goedhals L, Vorobiof DA, van der Merwe LA. Malignant pleural mesothelioma: a disease unaffected by current therapeutic maneuvers. J Clin Oncol 1988; 6: 527-535.

11. Dimitrov NV, McMahon S. Presentation, diagnostic methods, staging and natural history of malignant mesothelioma. In: Antman K, Aisner J, eds. Asbestos-related Malignancy. Orlando, Grune and Stratton 1987; pp. 225238.

12. International Mesothelioma Interest Group. A proposed new international TNM staging system for malignant pleural mesothelioma. Chest 1995; 108: 1122-1128.

13. Rusch VW, Venkatraman E. The importance of surgical staging in the treatment of malignant pleural mesothelioma. J Thorac Cardiovasc Surg 1996; 111: 815-826.

14. Sugarbaker DJ, Heher EC, Lee TH, et al. Extrapleural pneumonectomy, chemotherapy and radiotherapy in the treatment of diffuse malignant pleural mesothelioma. $J$ Thorac Cardiovasc Surg 1991; 102: 10-15.

15. Boutin C, Nussbaum E, Monnet I, et al. Intrapleural treatment with recombinant gamma-interferon in early stage malignant pleural mesothelioma. Cancer 1994; 74: 24602467.

16. Chailleux E, Pioche D, Chopra S, et al. Epidémiologie du mésothéliome pleural malin dans la région de NantesSaint-Nazaire. Evolution 1956-1992. Rev Mal Respir 1995; 4: 353-357.

17. Churg A. Chrysotile, tremolite and malignant mesothelioma in man. Chest 1988; 93: 621-628.

18. Boutin C, Dumortier P, Rey F, Viallat JR, De Vuyst P. Black spots concentrate oncogenic asbestos fibers in the parietal pleura. Am J Respir Crit Care Med 1996; 153: 444-449.

19. INSERM. Effets sur la santé des principaux types d'exposition à l'amiante. Expertise collective INSERM. Paris, Edition INSERM, 1997; p. 434.

20. McDonald JC, McDonald AD. The epidemiology of mesothelioma in historical context. Eur Respir J 1996; 9: 1932-1942.

21. Rey F, Viallat JR, Boutin C, et al. Les mésothéliomes environnementaux en Corse du Nord-Est. Rev Mal Respir 1993; 10: 339-345.

22. Iwatsubo Y, Pairon JC, Archambault de Beaune C, Chammings S, Bignon J, Brochard P. Pleural mesothelioma: a descriptive analysis based on a case-control study and mortality data in Ile de France 1987-1990. Am J Ind Med 1994; 26: 77-88.

23. Spirtas R, Beebe GW, Connelly RR, et al. Recent trends in mesothelioma incidence in United States. Am J Ind Med 1986; 9: 397-407.

24. Connelly RR, Spirtas R, Myers MH, Fraumeni JF Jr. Demographic patterns for mesothelioma in the United States. J Natl Cancer Inst 1987; 78: 1053-1060.

25. Armstrong BK, Musk AW, Baker JE, et al. Epidemiology of malignant mesothelioma in Western Australia. Med $J$ Aust 1984; 141: 86-88.

26. Hillerdal G. The pathogenesis of pleural plaques and pulmonary asbestosis: possibilities and impossibilities. Eur J Respir Dis 1980; 61: 129-135.

27. Ruffié P, Feld R, Minkin S, et al. Diffuse malignant mesothelioma of the pleura in Ontario and Quebec: a retrospective study of 332 patients. J Clin Oncol 1989; 7: 1157-1168.

28. Meijers JMM, Planteydt HT, Slangen JJM, Swaen GMH, van Vliet C, Sturmans F. Trends and geographical patterns of pleural mesotheliomas in the Nederlands 19701987. Br J Ind Med 1990; 47: 778-781.

29. McDonald JC. Health implications of environmental exposure to asbestos. Environ Health Perspect 1995; 62: 316-328.

30. Goldberg P, Goldberg M, Marne MJ, Hirsch A, Tredaniel $\mathrm{J}$. Incidence of pleural mesothelioma in New Caledonia. A 10-year survey (1978-1987). Arch Environ Health 1991; 46: 306-309.

31. McConnochie K, Simonato L, Mavrides P, Christofides P, Pooley FD, Wagner JC. Mesothelioma in Cyprus: the role of tremolite. Thorax 1987; 42: 342-347.

32. Sakellariou K, Malamou-Mitsi V, Haritou A, et al. Malignant pleural mesothelioma from non occupational asbestos exposure in Metsovo (north-west Greece): slow end of epidemic? Eur Respir J 1996; 9: 1206-1210.

33. Baris YI, Saracci R, Simonato L, Skidmore JW, Artvinli M. Malignant mesothelioma and radiological chest abnormalities in two villages in central Turkey. An epidemiological and environmental investigation. Lancet 1981; i: 984-987.

34. Hughes JM, Weill H. Asbestos exposure. Quantitative assessment of risk. Am Rev Respir Dis 1986; 133: 5-13.

35. Lilienfeld DE. Asbestos-associated pleural mesothelioma in school teachers: a discussion of four cases. Ann NY Acad Sci 1991; 643: 454-458.

36. Churg A, DePaoli L. Clearance of chrysotile asbestos from human lung. Exp Lung Res 1988; 14: 567-574.

37. Anttila S, Kadalainen A, Taikina-aho O, Kyyrönen P, Vainio H. Lung cancer in the lower lobe is associated with pulmonary asbestos fiber count and fiber size. Environ Health Perspect 1993; 101: 166-170.

38. De Vuyst P, Dumortier P, Moulin E, et al. Asbestos bodies in bronchoalveolar lavage reflect lung asbestos body concentration. Eur Respir J 1988; 1: 362-367.

39. Teschler H, Konietzko N, Schoenfeld B, Ramin C, Schraps T, Costabel U. Distribution of asbestos bodies in the human lung as determined by bronchoalveolar lavage. Am Rev Respir Dis 1993; 147: 1211-1215.

40. Roggli VL, Benning TL. Asbestos bodies in pulmonary hilar lymph nodes. Mod Pathol 1990; 3: 513-517.

41. Stanton MF, Layard M, Tegeris A, et al. Relation of particle dimension to carcinogenicity in amphibole asbestoses and other fibrous minerals. J Natl Cancer Inst 1981; 67: 965-975.

42. Pott F. Animal experiments on biological effects of mineral fibres. In: Wagner JC, ed. Biological Effects of Mineral Fibers. Lyon, IARC Scientific Publications, No. 30, 1980; pp. 261-269.

43. Goodglick LA, Kane AB. Cytotoxicity of long and short crocidolite asbestos fibers in vitro and in vivo. Cancer Res 1990; 50: 5153-5163.

44. Boutin C, Sebastien P, Janson X, Viallat JR. Métrologie des fibres minérales dans des biopsies thoracoscopiques pulmonaires et pleurales. Résultats préliminaires. Poumon-Coeur 1981; 37: 253-257. 
45. Dodson RF, Williams MG, Corn CJ, Brollo A, Bianchi C. Asbestos content of lung tissue, lymph nodes, and pleural plaques from former shipyard workers. Am Rev Respir Dis 1990; 142: 843-847.

46. Kohyama N, Suzuki Y. Analysis of asbestos fibers in lung parenchyma, pleural plaques, and mesothelioma tissues of North American insulation workers. NY Acad Sci 1991; 643: 27-52.

47. Kanazawa K, Roe FJC, Yamamoto T. Milky spots (taches laiteuses) as structures which trap asbestos in mesothelial layers and their significance in the pathogenesis of mesothelial neoplasia. Int J Cancer 1979; 23: 858-865.

48. Wang NS. Morphological data of pleura. Normal conditions. In: Chretien J, Bignon J, Hirsch A, eds. The Pleura in Health and Disease. New York, Masson, 1983; pp. 1024.

49. Fraire AE, Cooper S, Greeberg SD, Buffler P, Langston C. Mesothelioma of childhood. Cancer 1988; 62: 838847.

50. Boutin C, Rey F. Thoracoscopy in pleural malignant mesothelioma: a prospective study of 188 consecutive patients. Part 1: diagnosis. Cancer 1993; 72: 389-393.

51. Antman KH, Corson GM, Li FP, et al. Malignant mesothelioma following radiation exposure $J$ Clin Oncol 1983; 1: 695-700.

52. Zeng L, Fleury-Feith J, Monnet I, Boutin C, Bignon J, Jaurand MC. Immunocytochemical characterization of cell lines from human malignant mesothelioma. Hum Pathol 1994; 25: 227-234.

53. Renshaw AA, Dean BR, Antman KH, Sugarbaker DJ, Cibas ES. The role of cytologic evaluation of pleural fluid in the diagnosis of malignant mesothelioma. Chest 1997; 111: 106-109.

54. Whitley NO. Computed tomography and malignant mesothelioma. In: Antman K, Aisner J, eds. Asbestosrelated Malignancy. Orlando, Grune and Stratton, 1987; pp. 265-299.

55. Rusch VW, Gadwin JD, Shuman WP. The role of computed tomography scanning in the initial assessment and the follow-up of malignant pleural mesothelioma. J Thorac Cardiovasc Surg 1988; 96: 171-177.

56. Maasilta P, Vehmas T, Kivisaari L, Tammilehto L, Mattson K. Correlations between findings at computed tomography (CT) and at thoracoscopy/thoracotomy/autopsy in pleural mesothelioma. Eur Respir J 1991; 4: 952-954.

57. Patz EF Jr, Shaffer K, Piwnica-Worms DR, et al. Malignant pleural mesothelioma: value of CT and MR imaging in predicting resectability. Am J Roentgenol 1992; 159: 961-966.

58. Bittner RC, Felix R. Magnetic resonance (MR) imaging of the chest: state of the art. Eur Respir J 1998; 11: 13921404.

59. Boutin C, Rey F, Gouvernet J, Viallat JR, Astoul P, Ledoray V. Thoracoscopy in pleural malignant mesothelioma: a prospective study of 188 consecutive patients. Part II: Prognosis and staging. Cancer 1993; 72: 394-404.

60. Beauchamps HD, Kundra NK, Aranson R, Chong F, MacDonnell KF. The role of closed pleural needle biopsy in the diagnosis of malignant mesothelioma of the pleura. Chest 1992; 102: 1110-1112.

61. Galateau F, Letourneux M, Auriault ML, et al. Immunohistochemical diagnosis of pleural neoplasms. Eur Respir Rev 1993; 3: 33-37.

62. Doglioni C, Dei Tos AP, Laurino L, et al. Calretinin: a novel immunocytochemical marker for mesothelioma. Am J Surg Pathol 1996; 20: 1037-1046.

63. Donna A, Betta PG, Chiodera P, et al. Newly marketed tissue markers for malignant mesothelioma imunoreactivity of rabbit AMAD-2 antiserum compared with monoclonal antibody HBME-1 and a review of the literature on so-called antimesothelioma antibodies. Hum Pathol 1997; 28: 929-937.

64. Motoyama T, Watanabe T, Okazaki E, Tanaka N, Watanabe $\mathrm{H}$. Immunohistochemical properties of malignant mesothelioma cells in histologic and cytologic specimens. Acta Cytol 1995; 39: 164-170.

65. Boutin C, Viallat JR, Aelony Y. Practical thoracoscopy. Heidelberg, Springer. 1991; 1 Vol., p. 107.

66. Boutin C, Rey F, Viallat JR. Prevention of malignant seeding after invasive diagnostic procedures in patients with pleural mesothelioma. Chest 1995; 108: 754-758.

67. Antman KH, Shemin R, Ryan L, et al. Malignant mesothelioma: pronostic variables in a registry of 180 patients, the Dana-Farber Cancer Institute and Brigham and Women's Hospital experience over two decades 19651985. J Clin Oncol 1988; 6: 147-153.

68. Chahinian APH, Pajak TF, Holland JF, Norton L, Ambinder RM, Mandel EM. Diffuse malignant mesothelioma (prospective evaluation of 69 patients). Ann Intern Med 1982; 96: 746-755.

69. Chahinian AP. Therapeutic modalities in malignant pleural mesothelioma. In: Chrétien J, Hirsch A, eds. Diseases of the Pleura. New York, Masson, 1983; pp. 224-236.

70. Sugarbaker DJ, Strauss GM, Lynch TJ, et al. Node status has prognostic significance in the multimodality therapy of diffuse malignant mesothelioma. J Clin Oncol 1993; 11: 1172-1178.

71. Rusch VW, Saltz L, Venkatraman E, et al. A phase II trial of pleurectomy decortication followed by intrapleural and systemic chemotherapy for malignant pleural mesothelioma. J Clin Oncol 1994; 12: 1156-1163.

72. Sugarbaker DJ, Garcia JP, Richards WG, et al. Extrapleural pneumonectomy in the multimodality therapy of malignant pleural mesothelioma: results in 120 consecutive patients. Ann Surg 1996; 288-296.

73. Antman KH. Clinical presentation and natural history of benign and malignant mesothelioma. Semin Oncol 1981; 8: 313-320.

74. Wörn H. Chances and results of surgery of malignant mesothelioma of the pleura. Thorax-Chirurgie 1974; 22: 391-393.

75. Probst G, Buelzebruck H, Bauer HG, Branscheid D, Vogt-Moykopf I. The role of pleuropneumonectomy in the treatment of diffuse malignant mesothelioma of the pleura. In: Deslauriers J, Lacquet LK, eds. Surgical Management of Pleural Diseases, Vol. 6. St. Louis CV Mosby Co. 1990; pp. 344-350.

76. Aisner J. Current approach to malignant mesothelioma of the pleura. Chest 1995; 107: 332S-344S.

77. Hakkinen AM, Laasonen A, Linnainmaa K, Mattson K, Pyrhönen S. Radiosensitivity of mesothelioma cell lines. Acta Oncol 1996; 35: 451-456.

78. Linden CJ, Mercke C, Albrechtsson U, Johansson L, Ewers SB. Effect of hemithorax irradiation alone or combined with doxorubicin and cyclophosphamide in 47 pleural mesotheliorna: a non-randomized phase II study. Eur Respir J 1996; 9: 2565-2572.

79. Gordon W, Antman KH, Greenberger JS, Weichselbaum RR, Chaffey JT. Radiation therapy in the management of patients with mesotheliorna. Int J Rad Oncol Biol Phys 1982; 8: 19-25.

80. Ball DL, Cruickshank DG. The treatment of malignant mesothelioma of the pleura: review of a 5 year experience, with special reference to radiotherapy. Am J Clin 
Oncol 1990; 13: 4-9.

81. Low EM, Khoury GG, Matthews AW, Neville E. Prevention of tumour seeding following thoracoscopy in mesothelioma by prophylactic radiotherapy. Clin Oncol $(R$ Coll Radiol) 1995; 7: 317-318.

82. Sorensen PG, Bach F, Bork E, Hansen HH. Randomized trial of doxorubicine versus cyclophosplamide in diffuse malignant pleural mesothelioma. Cancer Treat Rep 1985; 69: 1431-1432.

83. Aisner J, Wiemik PH. Chemotherapy in the treatment of malignant mesothelioma. Semin Oncol 1981; 8: 335-343.

84. Ruffle P. Mesothelioma chemotherapy. Eur Respir Rev 1993; 3: 199-203.

85. Ong ST, Vogelzang NJ. Chemotherapy in malignant pleural mesothelioma: a review. J Clin Oncol 1996; 14: 10071017.

86. Zidar BL, Green S, Pierce HI, Roach RW, Balcerzak SP, Militello L. A phase II evaluation of cisplatin in unresectable diffuse malignant mesothelioma: a South West oncology group study. Invest New Drugs 1988; 6: 223-226.

87. Planting AST, Schellens JHH, Goey SH, van-der-Burg ME, de-Boer-Dennert M. Weekly high-dose cisplatine in malignant mesothelioma. Ann Oncol 1994; 5: 373-374.

88. Solheim OP, Saeter G, Finnanger AM, Stenwig AE. High dose methotrexate in the treatment of malignant mesothelioma of the pleura. A phase II study. Br J Cancer 1992; 6: 956-960.

89. Chahinian AP, Antman K, Goutsou M, et al. Randomized phase II trial of cisplatine with mytomycine or doxorubicine for malignant mesothelioma by the cancer and leukemia group B. J Clin Oncol 1993; 11: 1559-1565.

90. Breau JL, Boaziz C, Morère JF, Sadoun D, Israel L. Chemotherapy with cisplatin, adriamycin, bleomycin and mitomycin $\mathrm{C}$, combined with systemic and intrapleural hyaluronidase in stage II and III mesothelioma. Eur Respir Rev 1993; 3: 223-225.

91. Dimitrov NV, Egner J, Balcueva E, Suhrland LG. High dose methotrexate with citroverum factor and vincristine in the treatment of malignant mesothelioma. Cancer 1982; 50: 1245-1247.

92. Kasseyet S, Boutin C, Astoul Ph, Sellier P, Nussbaum E. Chinliothèrapie du mésothéliome pleural malin (MPM). Résultats d'un essai de phase II d'une polychimiothérapie-PMFE. Rev Mal Res 1995; 12: R75.

93. Fitzpatrick DR, Manning LS, Musk AW, Robinson BW, Bielefeldt-Ohmann H. Potential for cytokine therapy of malignant mesothelioma. Cancer Treat Rev 1995; 21: 273-288.

94. Goey SH, Eggermont AM, Punt CJ, et al. Intrapleural administration of interleukin 2 in pleural mesothelioma: a phase I-II study. Br J Cancer 1995; 72: 1283-1288.

95. Ijzermans JNM, Marquet RL. Interferon gamma: a review. Immunobiology 1989; 179: 456-473.

96. Phan-Bich L, Buard A, Petit JF, et al. Differential responsiveness of human and rat mesothelioma cell lines to recombinant interferon gamma. Am J Respir Cell Mol Biol 1997; 16: 178-186.

97. Zeng L, Buard A, Monnet I, et al. In vitro effects of recombinant human interferon gamma on human mesothelioma cell lines. Int J Cancer 1993; 55: 515-520.

98. Mannel DN, Falk W. Interferon gamma is required in activation of macrophages for tumor cytotoxicity. Cell Immunol 1983; 79: 396-402.

99. Trinchieri G, Perussia B. Immune interferon: a pleiotropic lymphokine with multiple effects. Immunol Today 1985; 6: 131-133.

100. Weimar W, Bantje TA, Bron AO, Hilvering C, Bolhuis P, Schellekens H. Interferon therapy for pleural mesothelioma. In: De Maeyer E, Galasso G, Schellekens H, eds. The Biology of the Interferon System. Amsterdam, Elsevier/North Holland Biomedical Press, 1981; pp. 401-404.

101. Le J, Willcek J. Lymphokine-mediated activation of human monocytes: neutralisation by monoclonal antibody to interferon gamma. Cell Immunol 1984; 85: 278283.

102. Nathan CF, Muray HM, Wiebe M, Rubin BY. Identification of interferon gamma as the lymphokine that activates human macrophages oxidative metabolism and antimicrobial activity. J Exp Med 1983; 158: 670-689.

103. Yasumoto K, Myazaki K, Nagashima A, et al. Induction of lymphokine-activated killer cells by intrapleural instillations of rIL-2 in patients with malignant pleurisy due to lung cancer. Cancer Res 1987; 44: 2184-2187.

104. Robinson BWS. Asbestos and cancer: human natural killer cell activity is suppressed by asbestos fibers but restored by rIL-2. Am Rev Respir Dis 1989; 139: 897-901.

105. Manning LS, Bowman RV, Darby SB, Robinson BS. Lysis of human malignant mesotheliorna cells by natural killer and lymphokine-activated killer cells. Am Rev Respir Dis 1989; 139: 1369-1374.

106. Astoul Ph, Bertault-Peres P, Durand A, Catalin J, Vignal F, Boutin C. Pharmacokinetics of intrapleural recombinant interleukin 2 in immunotherapy for malignant pleural effusion. Cancer 1994; 73: 308-313.

107. Astoul PH, Viallat JR, Laurent JC, Brandely M, Boutin C. Intapleural recombinant IL-2 in passive immunotherapy for malignant pleural effusion. Chest 1993; 103: 209-213.

108. Driesen P, Boutin C, Viallat JR, Astoul Ph, Vialette JP, Pasquier J. Implantable access system for prolonged intrapleural immunotherapy. Eur Respir J 1994; 7: 19891992.

109. Astoul Ph, Viallat J, Ledoray V, Boutin C. Interleukine-2 administrée par voie pleurale dans le traitement du mesotheliome pleural malin (Abstract). Rev Mal Respir 1996; 112: R103.

110. Kucharczuk JC, Elshami AA, Zhang HB, et al. Pleural-based mesothelioma in immune competent rats: a model to study adenoviral gene transfer. Ann Thorac Surg 1995; 60: 593-597.

111. Smythe WR, Hwang HQ Elshami AA, et al. Treatment of experimental human mesothelioma using adenovirus transfer of the herpes simplex thymidine kinase gene. Ann Surg 1995; 222: 78-86.

112. Antman KH, Blum RH, Greenberger JS, Flowerdew G, Skarin AT, Canellos GP. Multimodality therapy for malignant mesotheliorna based on a study of natural history. Am J Med 1980; 68: 356-362.

113. Viallat JR, Rey F, Astoul Ph, Boutin C. Thoracoscopic talc poudrage pleurodesis for malignant effusions: a review of 360 cases. Chest 1996; 110: 1387-1393. 